\title{
Stream diversion and reinstatement on a mine backfill in tropical Borneo
}

\author{
A Kemp Aurecon Australia Pty Ltd, Australia \\ C Russell Aurecon Australia Pty Ltd, Australia
}

A Keith Aurecon Australia Pty Ltd, Australia

\begin{abstract}
The island of Borneo, of volcanic origin and lying astride the equator, presented the challenges of tropical wet seasons and volcanic soil to the relocation of a river to access coal seams, and subsequent reinstatement over the backfilled pit.

Working together, the mining contractor and engineers developed a robust approach to accessing over $1 \mathrm{mt}$ of coal that would otherwise have been sterilised by the river running over the seam. The process involved a staged approach including cutting off a river meander and training the river to maximise pit extent on the southern side of the river, relocation of the river through a large cutting to the north to mine under the original riverbed, backfill of the southern pit and reinstatement of the river similar to its original alignment on the mine backfill.

The river diversion and reinstatement presented numerous significant technical and social challenges. The tropical location meant even the dry seasons often had significant volumes of rainfall for the river to drain to the Java Sea, hampering earthworks, while the wet seasons saw considerable water flows and flooding having to be handled by the river in its various configurations. Borneo's geology is such that the local mine overburden material is not well suited to producing competent compacted earthworks. This meant regular importation of suitable material from Sulewesi at high cost for construction projects. Finally, the local indigenous community made use of the river as a water source and transport route, requiring attention to meeting their needs through all stages of the relocation and reinstatement.

The adopted solution utilised the contractor's expertise in getting the most out of the mine overburden and local material for earthworks construction combined with engineering hydraulic, geomorphology and geotechnical expertise. Working collaboratively, the combined expertise produced a low cost design to address the key risks of settlement, seepage, safety of adjacent open mine pit after reinstatement and changes to the river hydraulic gradient causing sediment regime changes and river scour. The final design, while maximising the use of uncontrolled backfill of the pit, used a limited thickness compacted mine overburden liner and an alignment and cross section that enabled the river to find its own alignment over time, but constrained it within limits to protect the adjacent pit. The provision of revegetation for the final alignment reinstated historic river amenity.
\end{abstract}

Now, some four years after construction of the backfill and river reinstatement, the design has proved effective in achieving the aims of managing these risks and achieving a safe and robust outcome, sensitive to the post-mining environment and the local community.

\section{$1 \quad$ Background}

The Satui Coal Mine, owned by PT Arutmin Indonesia (Arutmin), lies near the southern coastline of the island of Borneo within the Indonesian province of South Kalimantan (Figure 1). The mine, including the adjacent Arutmin pits produced some $16 \mathrm{~m}$ t of thermal coal in 2012.

In 2004, Arutmin proposed to the Indonesian Department of Mines and Energy a plan to mine coal lying underneath the bed of the Jelamu River. The proposal included temporary relocation of the river channel to 
the northeast and subsequent reinstatement on the backfilled mine pit. The proposal would allow access to more than $1 \mathrm{~m}$ t of coal that otherwise would have been sterilised by the need to maintain buffer distances and stable pit slopes to the south and north of the river.

The proposed approach was phased as follows:

- Phase 1 - mining south of the Jelamu River (Abumanyu Pit) (Figure 2).

- Phase 2 - straighten the Jelamu River temporarily by cutoff channels to meanders in the river and mining out of the Abumanyu Pit (Figure 2).

- Phase 3 - divert Jelamu River (Phase 3 diversion) to the northeast and mine reserves from beneath original river alignment (Figure 3).

- Phase 4- reinstatement of Jelamu River close to original alignment (Figure 3).

Arutmin engaged the authors (through the company Aurecon - at the time Connell Wagner) to assist with engineering elements of Phases 2 to 4.

The river drained a sizeable catchment of some $136.6 \mathrm{~km}^{2}$ with high flood flows. In addition, it provided a source of water to local villages along the river and was also a transport route for communities using small boats. This paper focuses on the specific challenges, design solutions and outcomes after several years in service of the Phase 4 reinstatement.

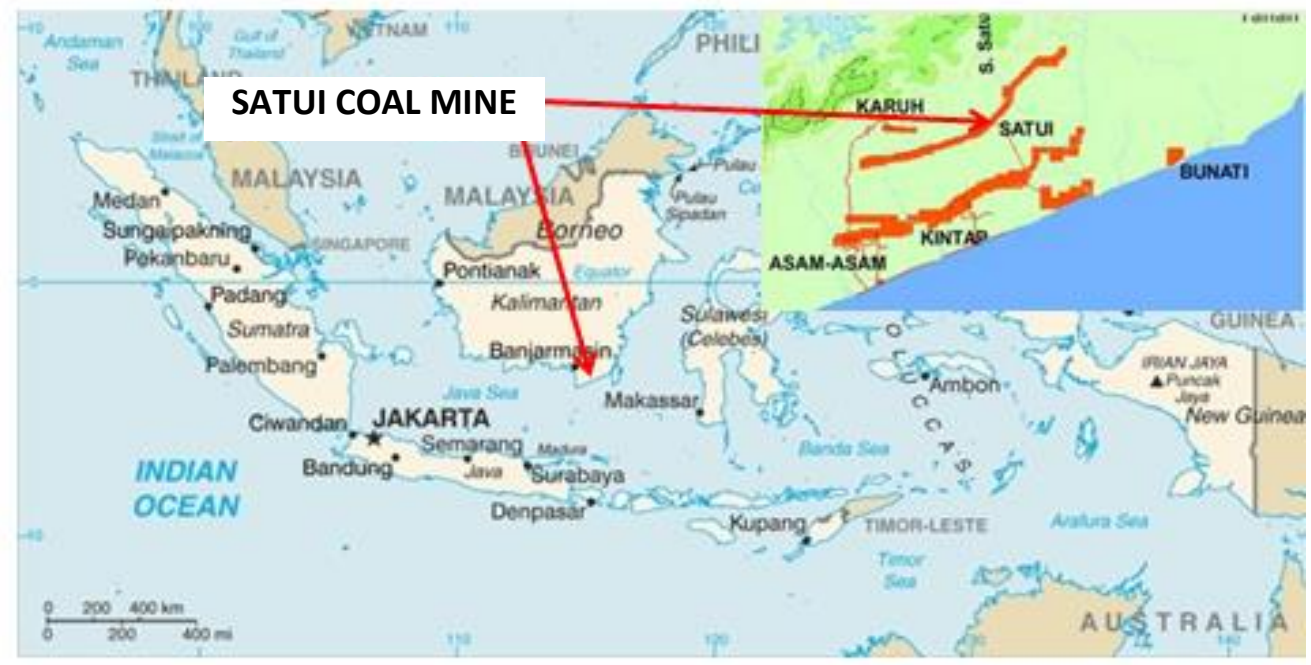

Figure 1 Satui coal mine location
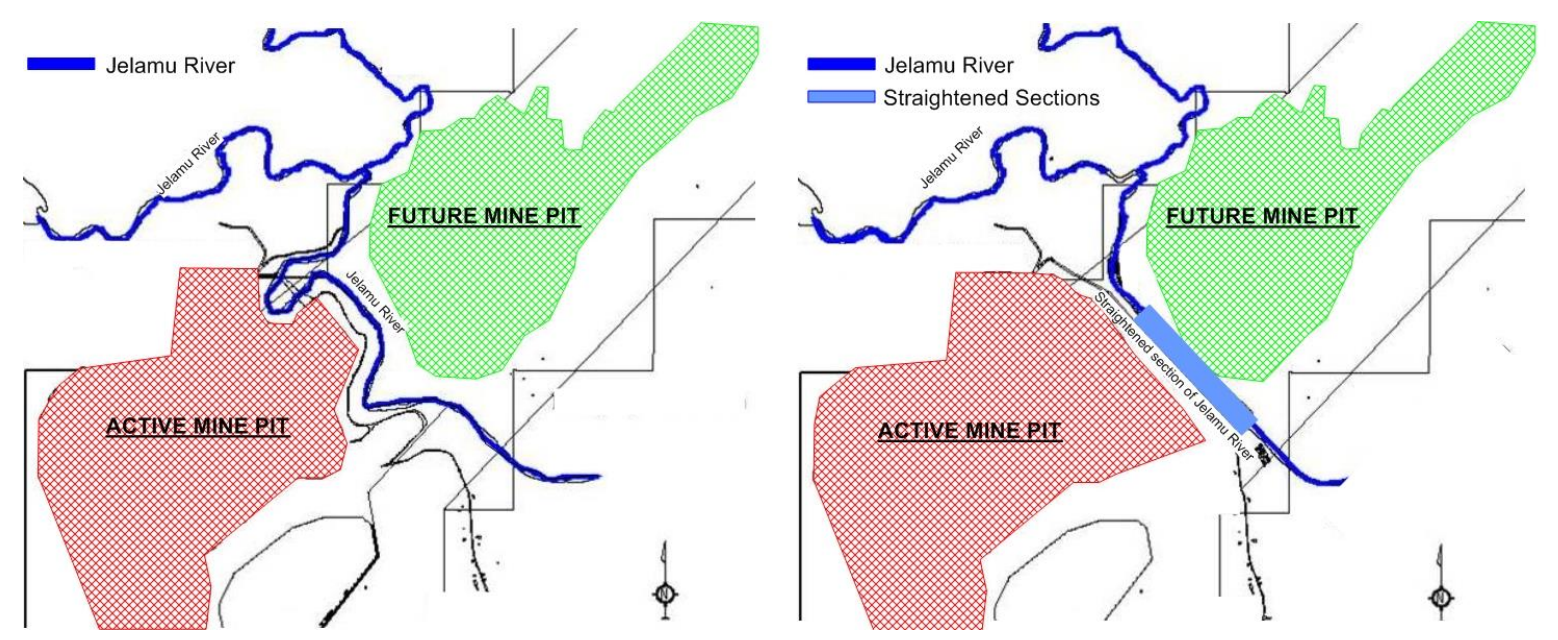

Figure 2 Phase 1 (left) - mining south of the natural river; and Phase 2 (right) - straighten river channel 

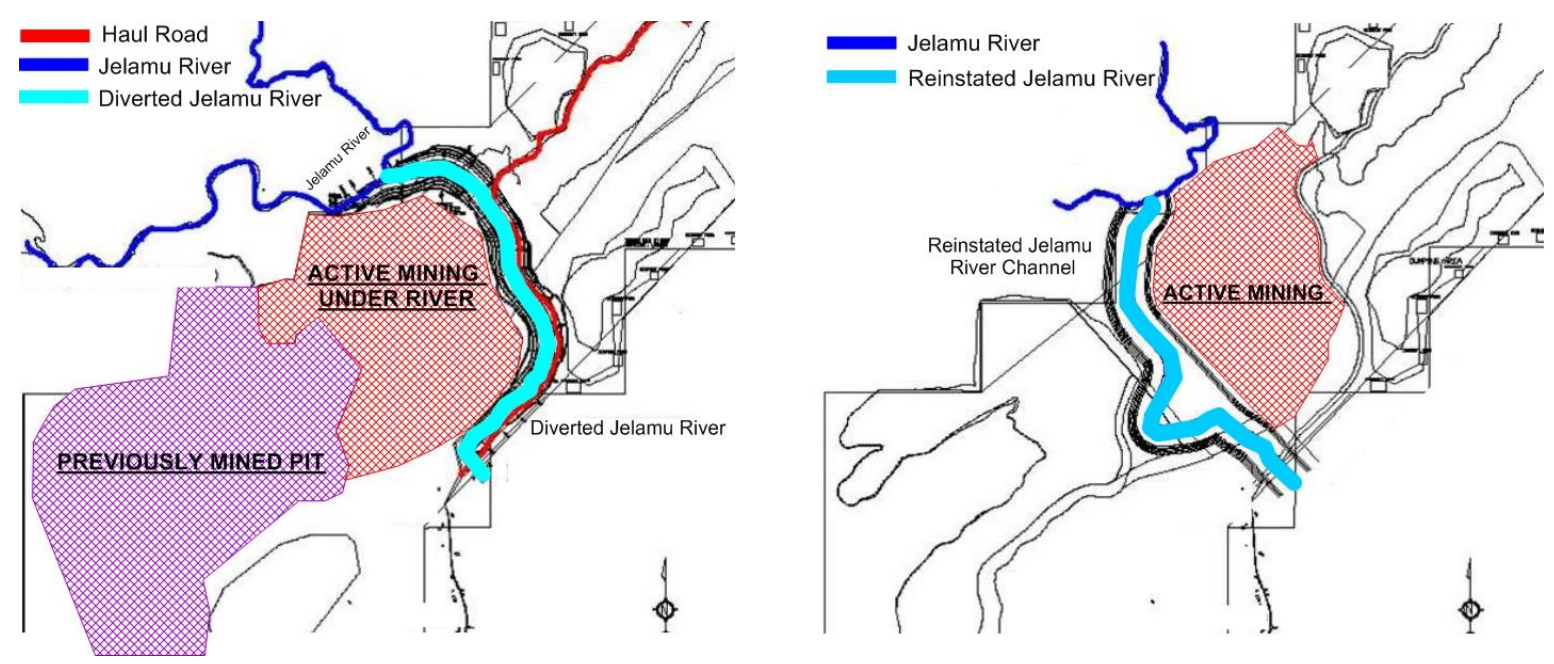

Figure 3 Phase 3 (left) - divert channel and mine under river; and Phase 4 (right) - channel reinstatement

\section{2}

\section{Literature review}

A literature review identified several successful examples of channels constructed on backfill. These were typically for minor waterways draining smaller catchments in lower rainfall areas. There was no identification of case studies for a major river of waterway in a high rainfall tropical zone.

A Rehabilitation Manual for Australian Streams (Rutherfurd et al. 2000) advocated that a 'whole of catchment' approach be adopted in determining the stream rehabilitation. It suggested that using natural condition 'templates' from the existing stream to design what the rehabilitated stream should look like. In particular Rutherfurd et al. (2000) noted that stream systems are highly dynamic and continually adjusting to variations in the processes that shape them. Furthermore, while engineers have developed equations that can be used to design a stable channel given certain conditions of bed material transport and hydrology, these equations have a high degree of uncertainty associated with them, even under ideal conditions when detailed data on the design variables are available.

Grady and Bethune (2003) presented a paper on the permanent diversion of Back Creek, Queensland through spoil. This paper outlined the approach to reinstating a stream on coal mine spoil associated with the Milmerran power station utilising the "Reference Reach" method described by Rutherfurd et al. (2000) utilising an alignment with similar slope and meanders and bed material to the natural Back Creek. In this project the mine overburden was placed and allowed three to five years for settlement and consolidation to occur after which the diversion channel would then be constructed. The channel was then to be allowed 15-20 years for further consolidation before the Back Creek was diverted into the channel. These timeframes would be clearly unacceptable for the Satui project.

A key constraint for the project was the geotechnical aspects relating to the settlement of the mine overburden. Case histories outlined in Charles and Watts (2001) were reviewed. This paper documented a the outcomes from filling a $60 \mathrm{~m}$ mine pit with mudstone, siltstone and sandstone with only the top $16 \mathrm{~m}$ compacted. For this case study settlement of $220 \mathrm{~mm}$ over the first 10 years was observed. Following a rise in the water table a further $300 \mathrm{~mm}$ settlement occurred.

The literature review clearly indicated that even under ideal conditions, considerable challenges exist for such river reinstatements over mine backfill. The additional challenges of the Jelamu River reinstatement included:

- The proposed timeframe did not allow for long periods of consolidation settlement before rediverting the river to the reinstated channel. To be of value to Arutmin the mining under the river and subsequent reinstatement had to fit with the overall mining plan for the pits being 
mined in a generally northeasterly direction. The time from completion of mine backfilling and construction of the reinstatement channel and rediversion of the river was less than three years.

- The hydrologic conditions were far from ideal due to limited data availability for the stream and catchment consisting of a daily rainfall record from the mine establishment only. No pluviograph or stream gauging data was available to assist in model validation.

- The catchment was large and storm rainfall intensities high, especially during wet seasons.

- The river gradient is relatively flat, such that large differential settlements between the reinstated zone and the downstream zone could cause unpredictable outcomes for the river channel.

\section{3}

\section{Hydraulics and geomorphology}

\subsection{Background}

The authors' mandate was to hydraulically design the river modification and diversions for Phases 2, 3 and 4. A key challenge for the reinstatement design was to reinstate (redivert) the Jelamu River back to near its original alignment prior to mining operations, and deal with the challenge of mine backfill material forming the foundation. Significant settlement of the backfill material could be expected to occur (refer Section 4), with the potential to cause instability and/or failure of a typical engineered diversion channel.

Whilst the Phase 3 diversion channel was a nominal trapezoidal channel (Figure 4), the natural river upstream and downstream was an incised low flow channel with little evidence of inset terraces or higher level terraces. Larger floods would break out onto the surrounding floodplain. Frequent bedrock outcropping was noted upstream, whilst the natural bed material was observed to be a poorly sorted mix of sand and cobble size particles (Figure 5). There was one haul road crossing of the Phase 3 diversion towards the downstream end which created a significant backwater effect (Markham, 2004).

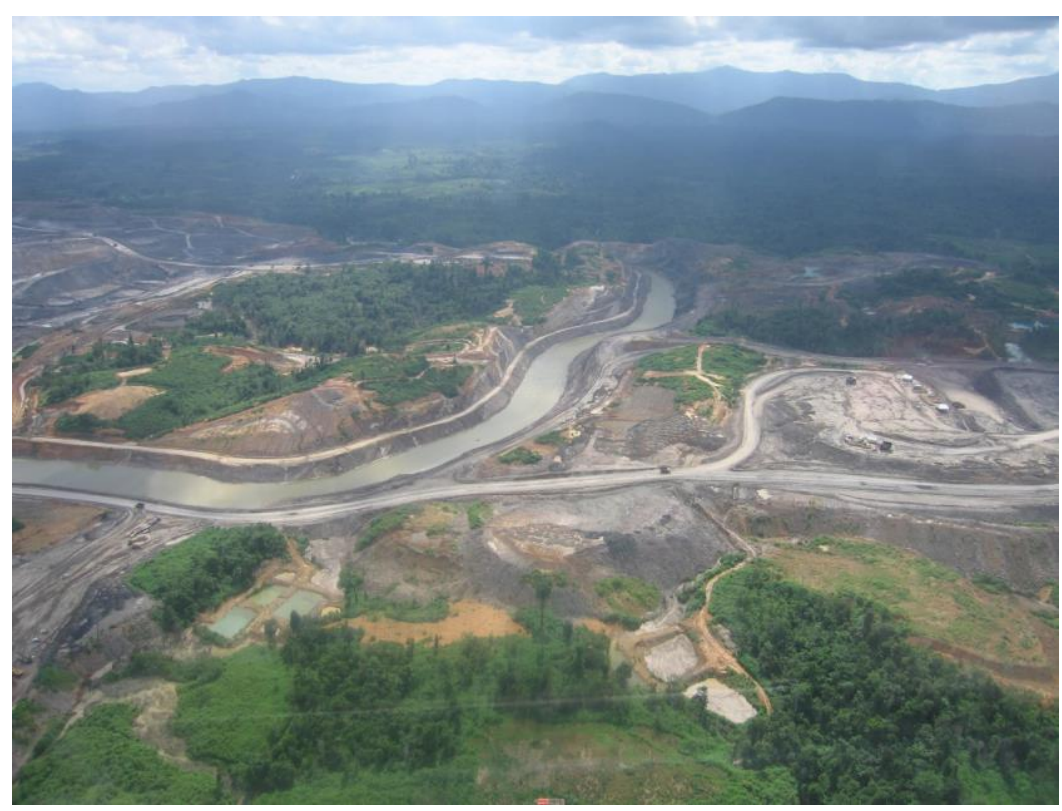

Figure 4 Trapezoidal diversion channel in operation 


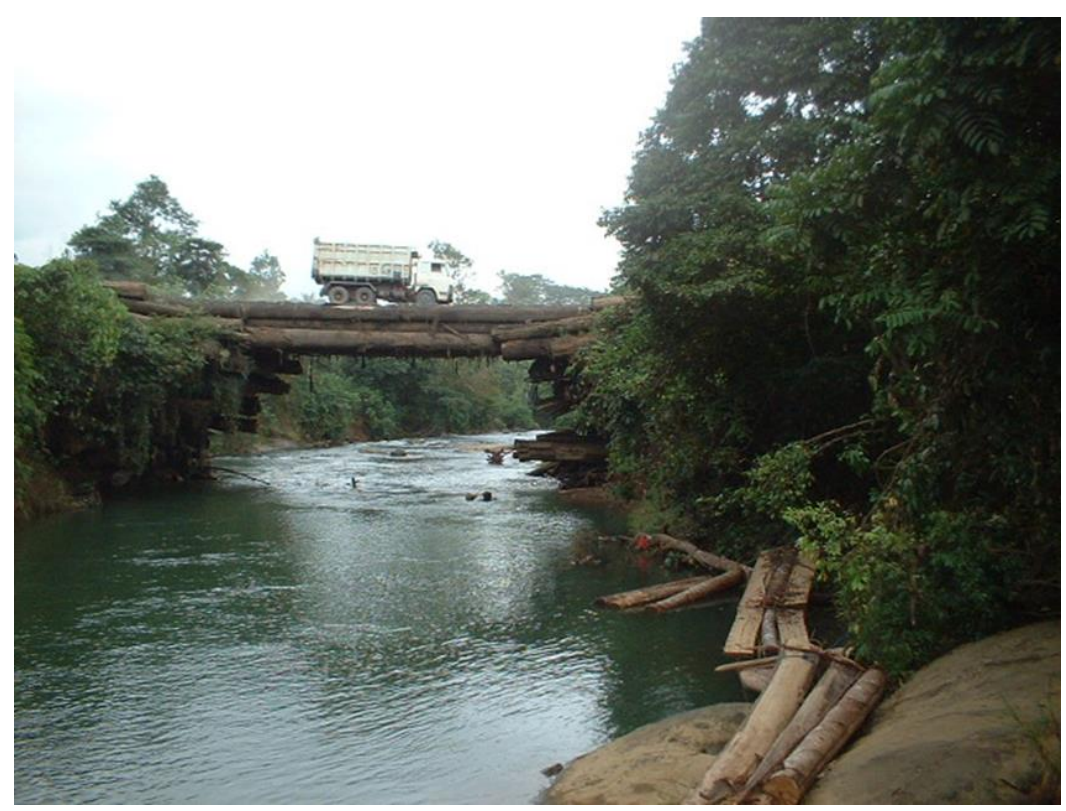

Figure 5 Incised natural channel upstream of diversion

\subsection{Design criteria}

In conjunction with Arutmin, the following design criteria were set for the reinstated channel:

- Solution must be cost effective (lowest cost preferable).

- Overall reinstated channel behaviour must be predictable.

- Channel to be allowed to erode, aggrade and migrate within acceptable limits - outer bunds to be provided beyond which the channel must not deviate.

- No significant increase in flood levels upstream of the reinstated channel.

- Haul road causeway crossing to be included towards downstream end but the design must allow for the potential for this to ultimately be washed away after mine closure.

- Channel should be self-maintaining (i.e. should develop an equilibrium form and ecosystem).

- Natural revegetation/regeneration should be enhanced.

- Community amenity of water supply quantity and quality and availability for small boat transportation to be maintained.

The design flows for the Jelamu River are summarised in Table 1.

\section{Table 1 Jelamu River design flows}

\begin{tabular}{cc}
\hline $\begin{array}{c}\text { Average recurrence } \\
\text { interval (years) }\end{array}$ & $\begin{array}{c}\text { Peak flowrate at } \\
\text { site }\left(\mathbf{m}^{\mathbf{3}} \mathbf{s}\right)\end{array}$ \\
\hline 1 & 271 \\
5 & 342 \\
10 & 385 \\
20 & 454 \\
50 & 545 \\
100 & 606 \\
\hline
\end{tabular}


Further issues to be considered in the design included:

- The risk of catastrophic channel avulsion.

- Design must be able to cope with large settlements/differential settlements. Settlement that leads to a step developing in the channel is unlikely to be a concern in the long-term as it would fill. However a major concern would be settlement near the outer bunds that might direct the main channel towards them causing lateral erosion and increased risk of breaching. There was therefore a need for adequate construction/protection of bund sidewalls and toes (below constructed surface level).

- Longevity and performance of haul road crossing, plus risk of culverts blocking with debris.

- Any solution would likely reduce downstream sediment loads, thus causing downstream scour.

- Potential seepage to active adjacent mine pit areas.

\subsection{Options development}

Various channel options were developed and assessed, with the final preferred option being an engineered trapezoidal two-stage channel. This is a fairly traditional design involving a low flow that may include meanders as appropriate, contained within a broader trapezoidal channel designed to pass a major flood event. The design also includes: outer bunds on the channel to protect outlying land from flooding; and culverts as a permanent/semi-permanent feature; and the provision of inlet and outlet control structures. Once selected, this option was subjected to further consideration and analysis, including consideration of the detailed geotechnical investigations (refer Section 4) plus hydraulic and shear stress/stream power analysis using the HECRAS (US Army Corps of Engineers 2010) backwater model.

For the preferred option, a key hydraulic criterion for the diversion in the backfill was to keep within threshold values of $1.5 \mathrm{~m} / \mathrm{s}$ and $20-30 \mathrm{~N} / \mathrm{m}^{2}$ under the design event (up to ARI 1 in 50 years). Furthermore, the satisfaction of this criterion needed to occur both with and without the haul road causeway/culvert in place (i.e. allowing for the culvert to be washed away in the future). A workable solution was found using a two-stage channel with the following features (Figures 6 and 7):

- Low flow channel - $30 \mathrm{~m}$ base width; $1 \mathrm{~V}: 4.5 \mathrm{H}$ side slopes and $5 \mathrm{~m}$ depth.

- High flow channel - $175 \mathrm{~m}$ base width; $1 \mathrm{~V}: 3.5 \mathrm{H}$ side slopes and $4 \mathrm{~m}$ depth (not including low flow).

- Outer bund walls - incorporated substantial rock protection including toe berms.

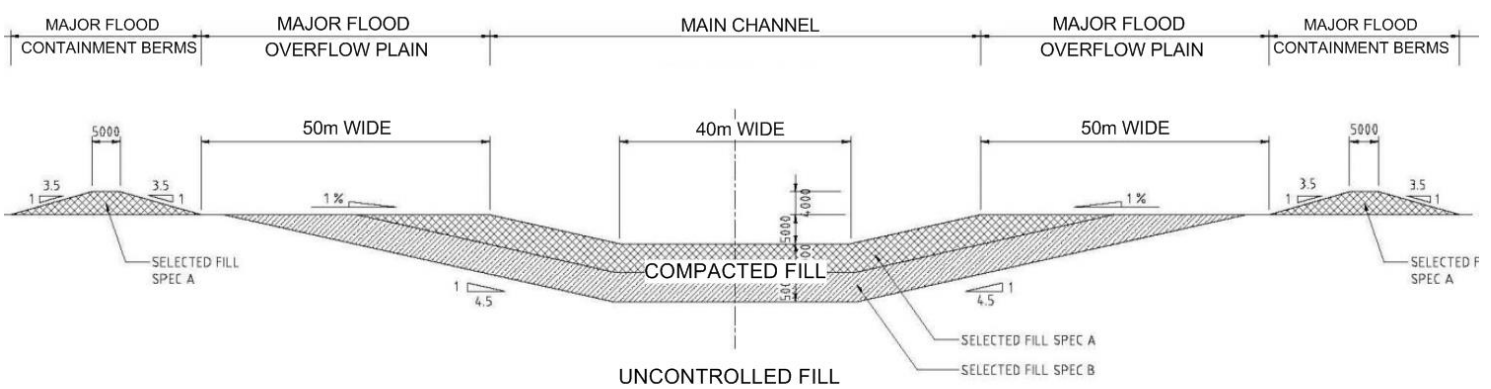




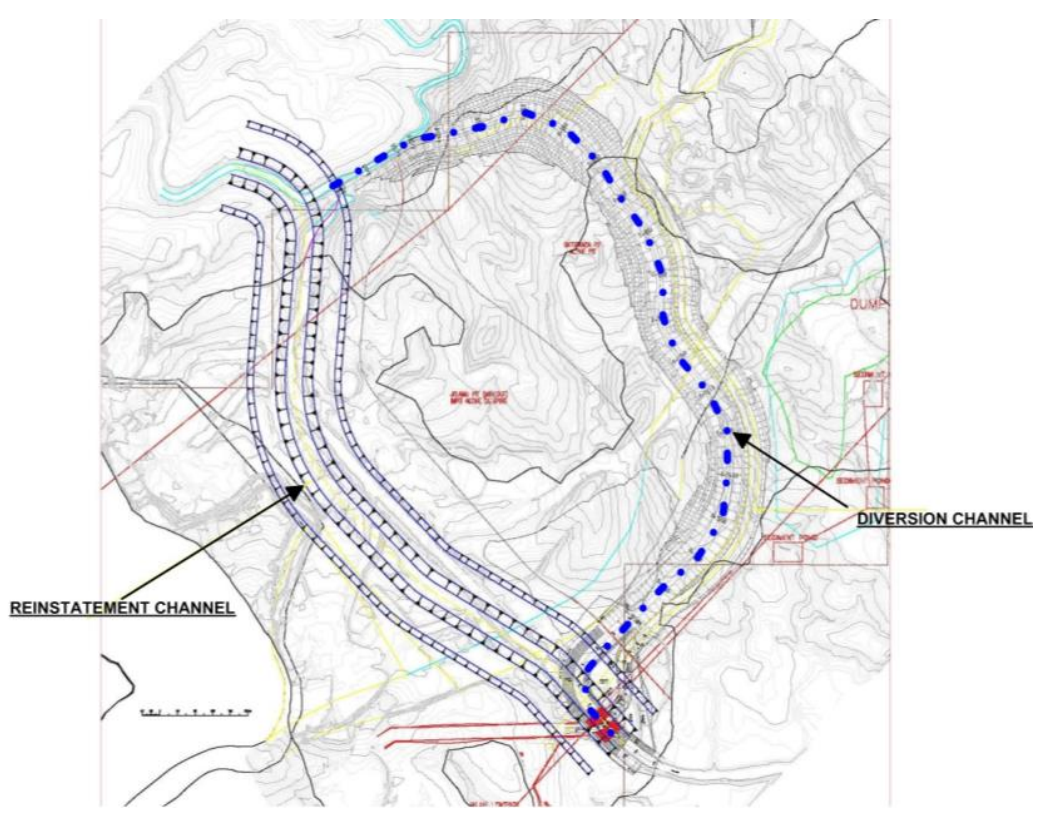

Figure 7 Selected design option plan - showing relationship between diversion and reinstatement channels and the downstream haul road crossing

\section{$4 \quad$ Geotechnical}

\subsection{Background}

Geotechnical investigations, interpretation and numerical modelling were required to study reinstatement options for the proposed diversion. The proposal was to construct the diverted channel on the filled Jelamu mine pit - estimated to be up to $65 \mathrm{~m}$ deep. The following key geotechnical issues or risks relating to the diversion were identified at the inception of the design:

- Settlement of the uncompacted fill materials. Excess total and differential settlement would have a significant impact on the behaviour of the river, its low flow channel, and overbank areas.

- Seepage through the base and side of the channel and its impact on mining operations.

- Scouring and erodibility of the channel lining material due to the flow velocity could also cause problems to the channel stability.

- Stability of the fill batters and its impact on mining operations.

The following sections describe the investigation, analysis and design process adopted in the development of the final solution.

\subsection{Geotechnical investigations}

In August 2004, a geotechnical investigation was carried out at three nearby backfilled pits that were likely to have similar properties to the proposed backfilled Jelamu pit. The investigations were commissioned to provide a clearer understanding of the classification, strength and permeability properties of the backfilled pit materials.

The field investigations comprised a combination of boreholes, test pits and trench pits. Disturbed samples collected from this investigation underwent Atterberg limits, particle size distribution, and Emerson class and standard proctor compactions testing. The investigation also assessed the in situ density and permeability of the natural soil and backfill materials via sand replacement tests and field percolation tests. The results of the field and laboratory tests indicate that the backfill material in each of the pits was highly variable. The backfill material comprised generally clay, silt, sand and gravel encountered at various depths. 
Due to the end-tipping nature of the backfill, there was no consistent stratigraphy and the sequence of materials could be described as random. The consistency of the cohesive soil found in the backfill was firm to stiff, whereas the cohesionless soils were typically medium dense. The cohesive soils were mostly low to medium plasticity with a few high plasticity zones.

The particle size distribution of the backfill materials showed a large amount of scatter. The range of composition was $20-50 \%$ gravel, $20-30 \%$ sand, $20-30 \%$ silt and $10-25 \%$ clay.

\subsection{Settlement behaviour of reinstated fill}

\subsubsection{Background}

Deep mine pit backfills are subject to large magnitudes of settlement by the following two mechanisms:

- Creep settlement.

- Collapse settlement.

On completion of the backfilling, significant long-term settlement occurs under conditions of constant stress and moisture content. The mechanism for creep settlement is one of gradual rearrangement of the material fragments resulting in a reduction in voids ratio due to the crushing of highly stressed contact points.

Collapse settlement occurs on inundation of a body of fill by ground or surface water. In the case of open cast backfill this can occur at depth on cessation of any pumping operations, or close to ground level as surface water penetrates into the fill. Field observations and research have shown that inundation is a major contributor of fill settlement especially with uncompacted open cast backfills.

The estimation of creep and collapse settlement magnitudes is largely empirical, based on databases of settlements measured at other sites. Table 2 summarises the important factors that influence the magnitude of the long-term settlement.

Table 2 Factors governing the magnitude and duration of creep and collapse settlement

\begin{tabular}{ccc}
\hline Factor & \multicolumn{2}{c}{ Effect on magnitude of creep settlement } \\
\cline { 2 - 3 } & Low value & High value \\
\hline Age of fill & Recent fill $\uparrow$ & Old fill $\downarrow$ \\
Depth and extent of fill & Small fill thickness $\downarrow$ & Large fill thickness $\uparrow$ \\
Nature and quality of fill & Soft rock/clay $\uparrow$ & Hard rock/sand $\downarrow$ \\
State of compaction & Poor compaction $\uparrow$ & Good compaction $\downarrow$ \\
Location of the water table or presence of water inflows & Inundation $\uparrow$ & Dry $\downarrow$ \\
\hline
\end{tabular}

Relating to Table 2, for the proposed Jelamu backfill material; the river will be diverted two years after filling; the depth of fill is up to $65 \mathrm{~m}$; the materials can be classified as soft sedimentary rocks (typically mudstone, siltstone and sandstone); the material will be end dumped and receive limited compaction and the diverted river will provide water inflows into the material. Via this simplistic assessment it was clear that the magnitude of future settlement was expected to be large.

Due to the large expected settlements and the potential impact it would have on the river diversion, it was decided that there was a need to provide an engineered solution. Compaction of the full depth of backfill would be uneconomic for the mine; therefore, an alternative solution was required. To minimise and control future settlements a zone of engineered (well compacted) fill the base of the reinstated channel in the backfill pit was proposed. 
The required depth of this engineered layer was assessed from both a settlement and seepage point of view. The following section summarises the settlement assessment.

\subsubsection{Estimation of creep settlement}

Creep settlement generally follows a log-time relationship that can be described by the general equation:

$$
s=\alpha \times\left(\log t_{2}-\log t_{1}\right)
$$

Where:

$$
\begin{aligned}
& \mathrm{s}=\quad=\text { settlement expressed as a percentage of the fill height. } \\
& t_{1} \text { and } t_{2}=\text { times from the beginning of the period of settlement. } \\
& \alpha=\text { creep compression rate which is defined as the amount of creep strain occurring } \\
& \text { within a log cycle of time. }
\end{aligned}
$$

Creep strains have been shown to be characterised by the creep compression rate with log-time and it is this characteristic that formed the basis of the method of predicting the creep component for the backfill settlement.

Average $\alpha$ values for systematically compacted backfill range from 0.1-0.3 for a number of sites examined in the UK (Hill and Denby 1996). Where no compaction was carried out, values in excess of 1.0 were recorded in some cases. Measurements by the Building Research Establishment (BRE) in the UK on an uncompacted mudstone, siltstone and sandstone open cast backfill also indicates that $\alpha=1 \%$ (Charles and Watts 2001).

To study the effect of the thickness of the engineered layer, several scenarios involving different zones of engineered and non-engineered fill were assessed based on a $\alpha$ value of 1 and $0.2 \%$, for uncompacted and well compacted backfill, respectively. The results of this assessment are presented in Figure 8 . In this assessment, it has been assumed that the creep settlement commences when half of the total height of backfill is completed which takes approximately six months to carry out.

\section{Years after backfilling is half completed}

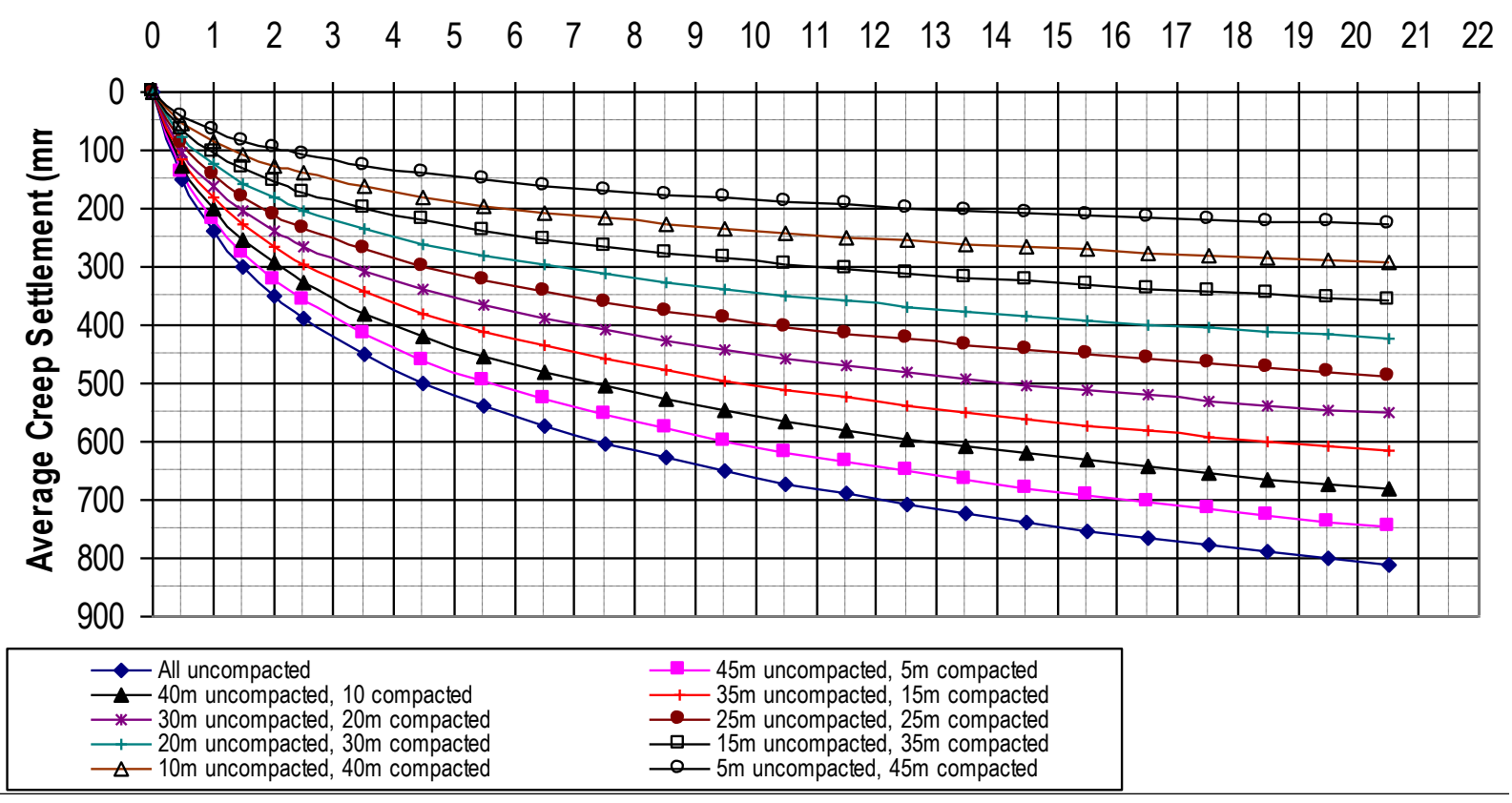

Figure 8 Results of creep settlement analysis for a range of uncontrolled fill depths 
Assuming the river flow was diverted back to the reinstated river after about two years, it was predicted the reinstated river may still undergo at least another $450 \mathrm{~mm}$ creep settlement up to 20 years with entirely uncompacted backfill. Creep settlement would still occur with time but at a slower rate. The magnitude of total creep settlement may be reduced by having certain zones of the backfill to be well compacted near the ground surface.

\subsubsection{Estimation of collapse settlement}

Collapse settlement is a phenomenon where fill materials, which have been inadequately compacted or placed excessively dry, undergo a reduction in volume when their moisture content is increased (Charles \& Watts 1996). This increase in moisture content can be caused either by downward infiltration of surface water or by a rising groundwater level. This phenomenon can occur without any increase in applied stress.

Collapse settlement has also been observed at many sites even when a full scheme of backfill compaction was carried out (Hill \& Denby 1996). Charles and Watts (1996) suggested the following observations made from a number of open cast mining backfill sites around the world:

- Ground movements due to collapse compressions may be large and vertical compressions in the order of 3-5\% are not unusual.

- Fills of different composition and arising in different circumstances can be vulnerable to collapse compression.

- Inundation can be due to either submergence from a rising groundwater level or river level, or water infiltrating downwards from the ground surface.

- Collapse compression can occur many years after the fill was placed.

The magnitude of the collapse potential of a particular fill is a function of both the past and present density and moisture content of the fill and the stresses to which it has been subjected. The collapse potential of fills placed by normal earthmoving plant decreases as placement density and moisture content increases; heavy compaction and placement at high moisture content should eliminate or at least greatly reduce collapse potential.

For the engineered fill layer solution, there is control over the compaction level and moisture content in the upper zone, thereby greatly reducing collapse potential within this zone. However, significant collapse settlement is still likely to occur in the uncompacted zone when it becomes inundated and this is very difficult to control. With the reinstated river to be constructed over the pit fill, it is highly likely that certain zones of the underlying fill would become inundated at some stage in the long-term even if a clay liner is provided.

Using empirical methods, the magnitude of collapse settlement was estimated to range from 0.4-1.2 $\mathrm{m}$ depending on the thickness of the compacted layer and was expected to be irregular and unpredictable with time.

\subsection{Seepage and stability analysis}

When the flow is rediverted back to the reinstated river, seepage will occur at the sides and under the river and has to be controlled in the long-term to limit the impact on the adjacent mining operation. Ongoing downward seepage from the diverted river was assessed to likely cause a localised mounding in the local groundwater level.

A parametric study was carried out to examine the relationship between the diverted river, the uncompacted and compacted backfill materials and the adjacent mining operation. The aim of the analysis was to evaluate the sensitivity of the permeability values, which were expected to be highly variable, and their impact on the local groundwater regime, mining operations and the fill slope stability. The effect of introduction of a well compacted fill layer on the seepage was also examined. 
The permeability of the fill materials was assessed using soil descriptions and the results of in situ permeability testing. The permeability was therefore derived in the following manner:

1. Bracketing of values from soil descriptions.

2. Developing a range of permeabilities from in situ testing.

The uncontrolled fill has been described as highly variable comprising clay, silt, sand and gravel. The geotechnical investigation report characterised the backfill as being predominantly gravel, sand, clay etc., but the material tends to be well graded and biased towards the coarser end of the sizing. Using this description, permeability of $10^{-4} \mathrm{~m} / \mathrm{s}$ was adopted for the uncontrolled fill. This permeability represented the global structure and did not take into account local effects. It was recognised that it was highly likely that zones of higher/lower permeability would be prevalent throughout the uncontrolled fill.

The permeability of the engineered fill layer was determined from the results of the in situ testing. A permeability of $10^{-6} \mathrm{~m} / \mathrm{s}$ represented a lower quartile value from this testing. This permeability was considered quite high for the grading and compaction criteria specified, therefore sensitivity analyses were also carried out to assess the effect that an improved permeability would have on the seepage flows into the mine pit and on the fill slope stability.

For the fill slope stability analysis, slope stability parameters were determined from a literature review on the shear strength of coal mine spoil and waste rock. These studies indicated a high degree of variability in the cohesion and friction angles, however, generally a lower bound a friction angle of $36^{\circ}$ is considered acceptable. A nominal cohesion of $1 \mathrm{kPa}$ was also adopted to model the effect of cohesive material within the fill matrix.

The results of the seepage and stability analysis showed the fill slope stability to be sensitive to the permeability of the engineered fill layer. Analysis showed that a maximum permeability of $10^{-7} \mathrm{~m} / \mathrm{s}$ was required to ensure an acceptable safety factor for the fill slope. Achieving this permeability minimised the mounding of groundwater within the backfill material and maintained batter stability. Furthermore, by maintaining this permeability the outflow of seepage into the mine pit could be kept to less than $10 \mathrm{~m}^{3} / \mathrm{m}$ of batter face/day.

\subsection{Final design}

Total settlements of well over $1 \mathrm{~m}$ were estimated likely to occur should the entire backfill depth comprise uncontrolled end-tipped fill. This order of magnitude of settlement will have significant effects on the river, such as:

- Formation of tension cracking in the fill which create preferential flow paths.

- Formation of a relatively high permeability material promoting water ingress into the mine pit.

- Increased requirements for dewatering in the operating mine pit due to water ingress.

- Lowering of the river bed level creating a pond effect on the hydraulic performance of the river.

- Differential movements may produce a scarp effect within the channel, which increases velocities and turbulence and could result in increased meandering.

- Need for settlement allowances within the construction design levels of the river banks and levees.

In addition to the impact of uncontrolled settlement, for uncontrolled, end-tipped fill, seepage flows from the diverted river would be uncontrolled, presenting a risk to the health and safety and operation of the adjacent mining operation.

Whilst a robust reinstated channel design is important, it is considered that differential movements, total settlement and seepage flows still need to be reduced to a manageable level. On the basis of the above 
issues it was considered to be good engineering practice to install an engineered, compacted fill layer or liner beneath the reinstated river to help mitigate the above effects.

The decision on the appropriate thickness of the engineered layer was made based on cost, the practicality of compacting mine back fill and the time impacts due to compaction. The design team worked with the mining contractor, Thiess, to evaluate the available mine overburden material, its suitability and the risks involved with its utilisation to develop a robust and cost effective design. South Kalimantan has a dearth of good granular material for competent compacted fill to form a base to reduce settlement potential to the channel. Such material is commonly imported from Sulewesi when needed for road construction and the like, at high cost. Design to maximise the use of local overburden material, and minimise or eliminate the need for high quality granular material was therefore a key goal of the design team.

Based on this assessment a $10 \mathrm{~m}$ thick engineered layer was finally adopted for the river diversion. The engineered fill layer was specified to contain a minimum of $30 \%$ fines (material passing $0.075 \mathrm{~mm}$ sieve) and be compacted to a minimum density of $95 \%$ maximum dry density (MDD) (standard compaction) at optimum moisture content (OMC) or $90 \%$ MDD at $120 \%$ OMC to minimise the risk of excessive creep and/or collapse settlement.

Furthermore, recognising that creep and collapse settlements could not be completely eliminated or significantly reduced (at an economic cost) any levees or flood mitigation structures were recommended incorporating an allowance of $700 \mathrm{~mm}$ to accommodate any potential future settlements.

A compacted over-burden fill buttress, with $1 \mathrm{~V}: 2 \mathrm{H}$ slopes and $5 \mathrm{~m}$ wide benches, was also nominated to be maintained to minimise instability of the fill slope during mining operations. Figure 9 presents the final typical design section for the reinstatement.

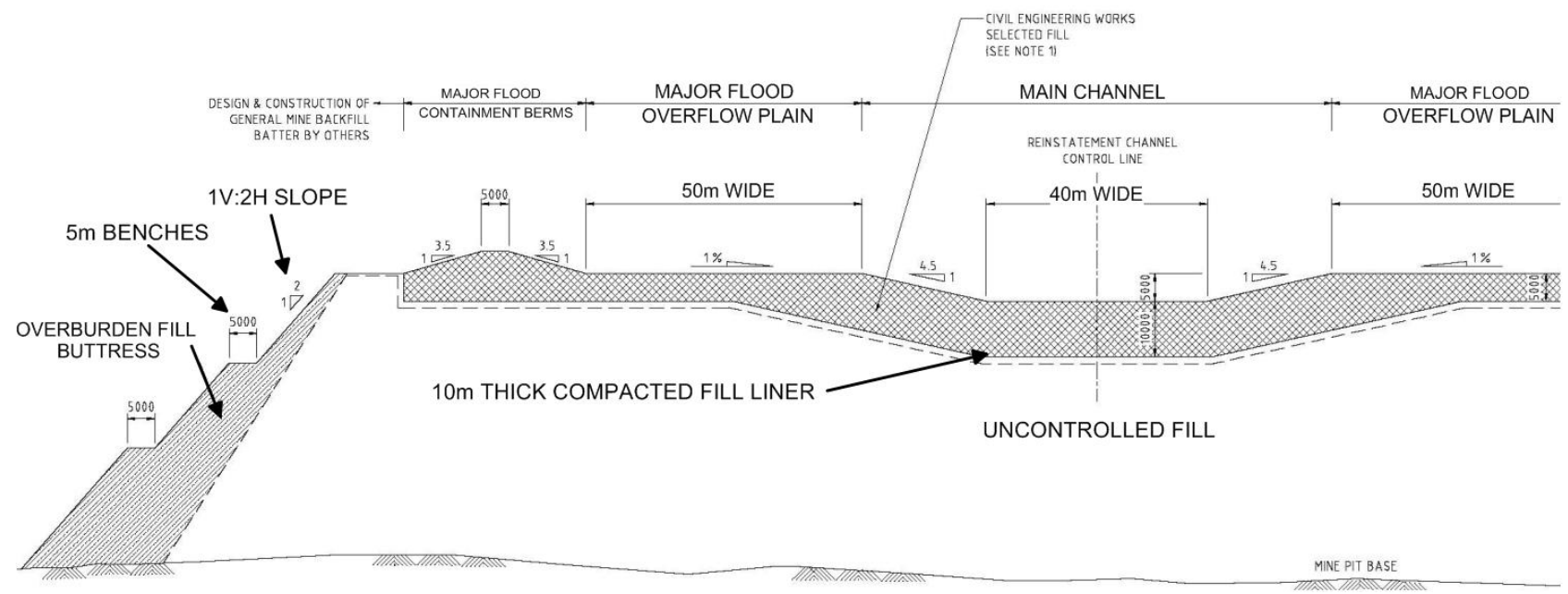

Figure 9 Reinstatement channel - final design typical cross section

\section{$5 \quad$ Mining and construction}

Mining and construction of the mine pits, diversion and reinstatement channel were undertaken by PT Thiess Contractors Indonesia (Thiess) under their life-of-mine mining contract with Arutmin.

The approach to the construction of the reinstatement channel over approximately a three year period included the following sequence:

- Diversion of the river to the diversion channel.

- Mining underneath the river bed and formation of the northern mining pit (Gatakaca Pit).

- Backfilling of the Jelamu Pit and river alignment by back tipping of mine overburden. 
- Construction of reinstatement channel using compacted select fill (as specified by the design for size grading, plasticity and permeability to limit differential settlement and seepage) starting from the upstream end. Compliance testing was undertaken throughout the construction period.

- Testing of the engineered layer showed that over $97 \%$ of samples exceeded the minimum fines requirement to ensure the minimum permeability requirements. Furthermore, testing showed that the compaction levels were also completed to the required standards.

- Infiltration testing of the final engineered layer was also undertaken to confirm that the minimum fines content in the fill material equated to the permeability values adopted in the channel design. This testing showed the final layer to have a vertical permeability equal to or exceeding the minimum requirement of $10^{-7} \mathrm{~m} / \mathrm{s}$.

- Plugging of the diversion channel and rediversion of the river flow back into the reinstatement channel.

A feature of the construction was the identification and stockpiling by Thiess of mine overburden materials to suit the general back dumped (uncontrolled) fill zone and the controlled select fill zone such that no imported fill material was required. The utilisation of on-hand mine overburden, both in the design assessment, and in the sorting of this material to suit the construction was a key feature in allowing the construction to be completed in a timely and cost-effective manner.

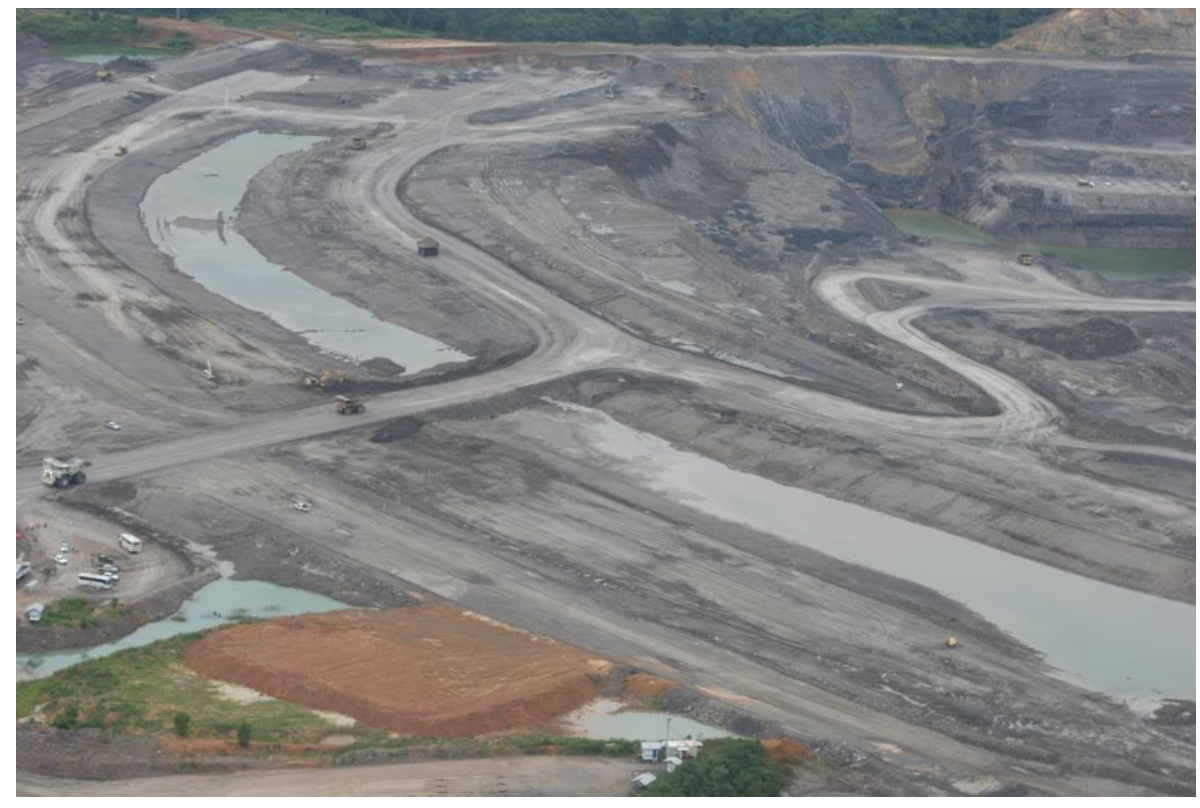

Figure 10 Construction of reinstatement channel at upstream end showing back tip uncontrolled filling of mine pit

\section{$6 \quad$ Outcomes}

The reinstatement channel has now been in operation for some four years. Mining at the southern end of the Gatakaca Pit is complete and mining activities have moved to the north. The revegetation of the reinstated river channel has been highly successful and the alignment of the channel has proved to be relatively stable through several wet seasons of fairly high flow events. Differential settlement of the channel has not been observed to be excessive such that channel stability or seepage into the adjacent mine pit has been adversely impacted. 


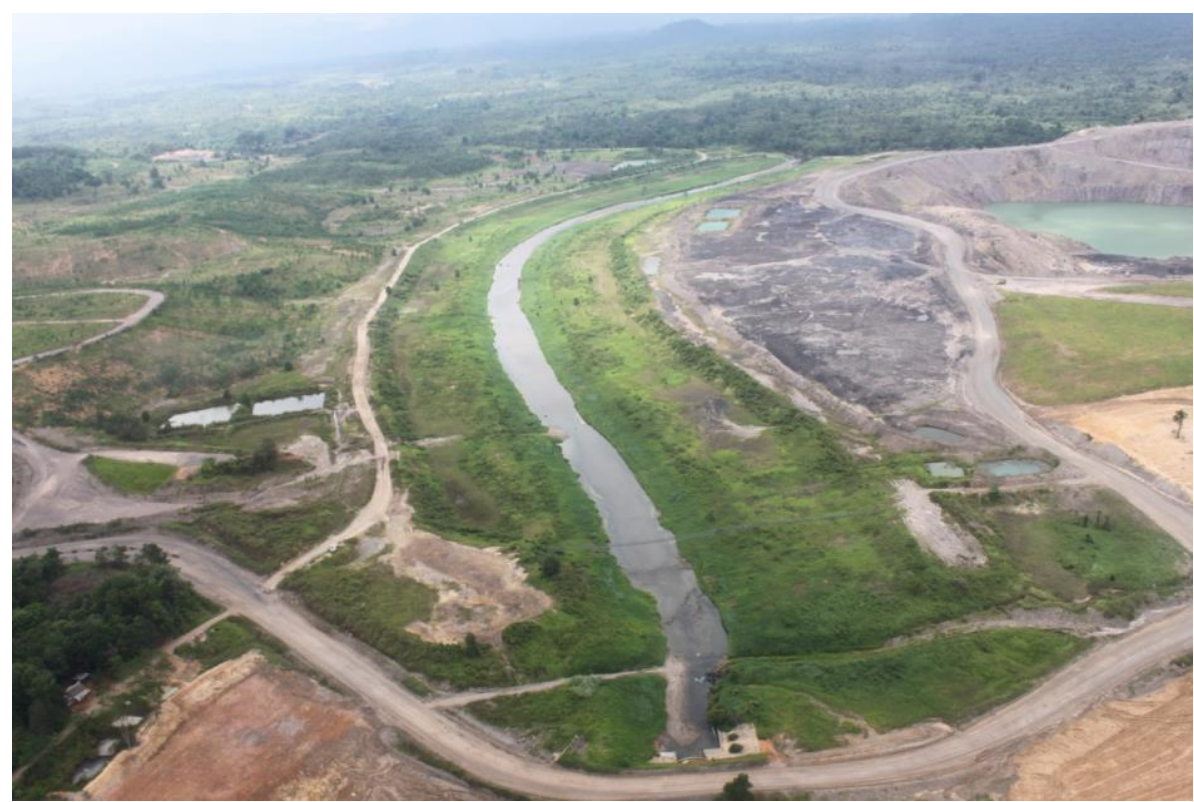

Figure 11 Reinstated channel in place and operating with mined out mine pit to the north (right of picture)

\section{Conclusion}

Despite considerable challenges of required construction time, mine overburden quality and hydrologic and geomorphic attributes of the river and catchment a collaborative approach between the mine owner, Arutmin, constructor, Thiess, and the design team resulted in a risk-based design utilising locally available materials for a low cost design solution. The solution has, in its four years since construction, stood the test of time.

\section{References}

Charles, JA \& Watts KS 1996, 'The Assessment of the Collapse Potential of Fills and its Significance for Building on Fill', Proceedings of the ICE - Geotechnical Engineering, vol. 119, no. 1, pp. 15-28.

Charles, JA \& Watts, KS 2001 Building on fill: geotechnical aspects, Construction Research Communications, Watford, Hertfordshire.

Grady, J \& Bethune, P 2003, 'Permanent Creek Diversion Through Spoil - Back Creek, Queensland', Proceedings of the Water in Mining Conference, Australasian Institute of Mining and Metallurgy, Carlton.

Hill CWW \& Denby, B 1996, 'The prediction of opencast backfill settlement', Proceedings of the Institution of Civil Engineers, Geotechnical Engineering, vol. 119, issue 3, pp. 167-76.

Markham, A August 2004, Geomorphic Assessment of Jelamu River Diversions and Reinstatement, fieldwork progress report submitted to CW-DC Pty Ltd (now Aurecon), prepared by Hydrobiology, Brisbane.

Rutherfurd, ID, Jerie, K \& Marsh N 2000, A Rehabilitation Manual for Australian Streams, vol. 1, Land and Water Resources Research and Development Corporation, Canberra, Australian Capital Territory, Cooperative Research Centre for Catchment Hydrology, Clayton, Victoria, viewed 24 February 2014, http://lwa.gov.au/files/products/river-landscapes/pr000324/ pr000324.pdf.

US Army Corps of Engineers 2010, HEC-RAS River Analysis System, Hydraulic Reference Manual, Version 4.1, US Army Corps of Engineers, Davis. 